\title{
Transmission of a Klebsiella pneumoniae clone harbouring genes for CTX-M-15-like and SHV-112 enzymes in a neonatal intensive care unit of a Kuwaiti hospital
}

\begin{abstract}
Correspondence
Ali A. Dashti

aad@hsc.edu.kw
\end{abstract}

Received 26 January 2010

Accepted 22 February 2010

\author{
Ali A. Dashti, ${ }^{1}$ Mehrez M. Jadaon, ${ }^{1}$ Huda H. Gomaa, ${ }^{2}$ Bobby Noronha ${ }^{3}$ \\ and Edet E. Udo ${ }^{3}$ \\ ${ }^{1}$ Department of Medical Laboratory Sciences, Faculty of Allied Health Science, \\ Health Sciences Centre, Kuwait University, Kuwait \\ ${ }^{2}$ Microbiology Laboratory, Al Jahra Hospital, Kuwait \\ ${ }^{3}$ Department of Microbiology, Faculty of Medicine, Health Sciences Centre, Kuwait University, \\ Kuwait
}

The spread of antibiotic-resistant bacteria has become a large problem in most countries including Kuwait. This antibiotic resistance is usually due to the production of extended-spectrum $\beta$-lactamase (ESBL) enzymes such as SHV, TEM and CTX-M. This study reports the emergence and spread of an ESBL-producing Klebsiella pneumoniae clone in a neonatal intensive care unit (NICU) in a Kuwaiti hospital. Eight ESBL-producing K. pneumoniae isolates were from blood cultures of seven neonates, and two were from the fingers of two healthcare workers in a NICU in Al Jahra Hospital, Kuwait. All isolates were obtained in February-March 2006, except for one, which was obtained in August 2005. Identification of the bacteria was based on traditional bacteriological and biochemical tests using the Vitek system. Antibiotic susceptibility was tested by the disc diffusion method using 16 different antibiotics. ESBLs were detected using disc approximation and double-disc synergy methods and confirmed as ESBLs using Etest. PCR and DNA sequencing were performed to determine the genotypes and mutations in the $\beta$-lactamase

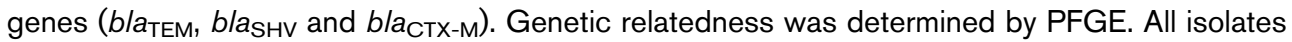
were confirmed to have ESBLs by the Vitek system, disc approximation test, double-disc diffusion test and Etest, being resistant to cefotaxime, ceftazidime, cefepime, gentamicin, tobramycin and ciprofloxacin but susceptible to tetracycline and trimethoprim-sulfamethoxazole. Molecular studies showed the isolates to have TEM-1 $\beta$-lactamase, a CTX-M-15-like ESBL and the newly discovered SHV-112 ESBL. PFGE showed that all isolates had identical banding patterns. The results indicate that a single clone of ESBL-producing $K$. pneumoniae caused bloodstream infections among babies in a NICU of a Kuwaiti hospital, and may have emerged at least 5 years ago. This clone was also present on the hands of healthcare workers, suggesting that they may have been involved in its transmission. Further studies are recommended to determine whether this clone is also spreading in other Kuwaiti hospitals.

\section{INTRODUCTION}

The excessive use of the oxyimino-cephalosporins in clinical practice has resulted in Klebsiella species and other members of the Enterobacteriaceae showing diminished susceptibility to them (Du Bois et al., 1995; Sanders et al., 1996; Heritage et al., 1999). Resistance to third-generation cephalosporins in these isolates is largely due to the production of extended-spectrum $\beta$-lactamase (ESBL)

Abbreviations: ESBL, extended-spectrum $\beta$-lactamase; NICU, neonatal intensive care unit. enzymes, which hydrolyse oxyimino-cephalosporins that are inhibited by clavulanic acid (Bradford, 2001). These enzymes are derived from the TEM-1/2 and SHV-1 family of $\beta$-lactamases (Bradford, 2001; Jacoby, 2006). The epidemiology of ESBLs has undergone dramatic changes in recent years with the emergence and spread of the CTXM-type enzyme worldwide (Bradford, 2001; Bonnet, 2004; Paterson \& Bonomo, 2005).The CTX-M enzyme was initially described in Germany and Argentina (Bonnet, 2004; Paterson \& Bonomo, 2005), but has now become widespread in both healthcare and community settings in 
Europe, Asia, South America and the USA (Canton \& Coque, 2006). The spread of CTX-M enzymes in healthcare environments is suspected to be due to the spread of multiple clones, as well as the spread of mobile genes among unrelated strains (Canton \& Coque, 2006). It is also possible that the enzymes have been introduced from the community into healthcare settings as the prevalence of faecal carriers of CTX-M-producing organisms has increased in the community (Valverde et al., 2004; BenAmi et al., 2006).

ESBL-producing strains of the Enterobacteriaceae have been reported to cause outbreaks of infections (Naseer et al., 2007; Shenoy et al., 2007) leading to serious antibiotic management concerns (Jonathan, 2005). Risk factors that have been associated with the acquisition of ESBLproducing organisms are usage of central venous or arterial catheters, emergency intra-abdominal surgery, and lung or gastrointestinal tract pathologies (Paterson et al., 2003).

The distribution of CTX-M enzymes varies among countries. For example, CTX-M-9 and CTX-M-14 are common in Spain, CTX-M-1 is prevalent in Italy and CTXM-2 is prevalent in most countries in South America, Japan and Israel, whereas CTX-M-15 is distributed worldwide (Canton \& Coque, 2006). In the Arabian Gulf countries (the Gulf Cooperation Council Countries), information on the types of ESBL is scanty (Sonnevend et al., 2006), although ESBL-producing members of the Enterobacteriaceae have been reported in Saudi Arabia (Panhotra et al., 2004; Kader \& Angamuthu, 2005; El-Khizzi \& Bakheshwain, 2006; Kader et al., 2007), Kuwait (Dimitrov et al., 2004; Jamal et al., 2005; Dashti et al., 2006; Dashti \& West, 2007), Oman (Rafay et al., 2007), Bahrain (Wallace et al., 1995) and the United Arab Emirates (Sonnevend et al., 2006; Al-Zarouni et al., 2008). Despite their widespread distribution, the prevalence of ESBL-producing organisms remains underestimated because a large number of laboratories do not perform routine tests that specifically detect ESBLs. In this study, we report on the isolation of CTX-M-15-like- and SHV-112-producing Klebsiella pneumoniae from neonates and healthcare workers in a neonatal intensive care unit (NICU) in $\mathrm{Al}$ Jahra Hospital in Kuwait.

\section{METHODS}

Bacterial isolates. Ten isolates of ESBL-producing K. pneumoniae were included in the study. All samples were obtained from Al Jahra Hospital, Kuwait, a 600-bed general hospital that serves a population of approximately 200000 , with 25 wards and a 53-bed NICU. The samples were eight isolates obtained from blood cultures from seven neonates, and two isolates from the fingers of two healthcare workers. The samples were collected between 2 February and 4 March 2006, except for one isolate, which was obtained from a blood culture of a neonate in the NICU in August 2005. Isolates were identified at the microbiology laboratory of Al Jahra Hospital using traditional bacteriological methods and biochemical tests, using the Vitek 2 GNI card following the manufacturer's recommendations (bioMérieux). The isolates were stored at $-80{ }^{\circ} \mathrm{C}$ in $15 \%$ glycerol $(\mathrm{v} / \mathrm{v})$ in brain- heart infusion broth. They were subcultured on nutrient agar and incubated aerobically at $37^{\circ} \mathrm{C}$ for $24 \mathrm{~h}$.

Antibiotic susceptibility testing. Antibiotic susceptibility testing was performed by the disc-diffusion method on Mueller-Hinton agar, which was incubated at $35{ }^{\circ} \mathrm{C}$ for $18 \mathrm{~h}$. The results were interpreted according to the current guidelines of the Clinical Laboratory Standards Institute (Naseer et al., 2007) The following antibiotics were tested: ampicillin, piperacillin, piperacillin-tazobactam, amoxicillin-clavulanate, cephalothin, cefuroxime, cefotaxime, ceftriaxone, cefoxitin, ceftazidime, gentamicin, amikacin, streptomycin, trimethoprim-sulfamethoxazole, ciprofloxacin, chloramphenicol and imipenem. Escherichia coli strain ATCC 25922 was used for quality control.

Detection of ESBL production. ESBLs were detected using the disc approximation and double-disc synergy methods and confirmed with cefotaxime and ceftazidime Etest ESBL strips (AB Biodisk). For the disc approximation test, clavulanate diffusion from an amoxicillinclavulanate (AMC30) disc was used to test for synergy with cefotaxime, ceftazidime, cefuroxime, cefepime and cefixime (Oxoid) as described previously (Sonnevend et al., 2006). For the double-disc synergy test, a ceftazidime disc $(30 \mu \mathrm{g})$ was placed $30 \mathrm{~mm}$ away from a disc containing amoxicillin-clavulanate $(60 / 10 \mu \mathrm{g})$. ESBL production was considered positive when an enhanced zone of inhibition was visible between the $\beta$-lactam and $\beta$-lactamase inhibitor-containing discs (Cormican et al., 1996; Livermore \& Yuan, 1996). For the Etest, ESBL strips containing ceftazidime and ceftazidime-clavulanate and strips containing cefotaxime and cefotaxime-clavulanate were used to determine the MIC ratio according to the manufacturer's instructions ( $\mathrm{AB}$ Biodisk). Cultures were incubated aerobically at $37{ }^{\circ} \mathrm{C}$ for $18-24 \mathrm{~h}$.

Amplification of ESBL genes. The presence of $\beta$-lactamase genes was investigated by PCR assays. Primers used to amplify the $b l a_{\mathrm{TEM}-1}$ gene were blaTEM1 (5'-CTGGGAAACGGAACTGAATG-3') and blaTEM2 (5'-GGGGTATCCCGCAGATAAAT- $\left.3^{\prime}\right)$. Primers used to amplify the bla $a_{\mathrm{SHV}}$ gene were blaSHV1 (5'-ATGAGTATTCAACATTTCCG-3') and blaSHV2 (5'-CCAATGCTTATTCAGTGAGG-3') (Hanson et al., 1999). Sequences for the $b l_{\mathrm{CTX}-\mathrm{M}-1}$ gene primers were 5'-GACGATGTCACTGGCTGAGC-3' and 5'-AGCCGCCGACGCTAATACA-3'. The TEM and CTX-M-1 primers were prepared in house. PCR conditions for the SHV gene comprised an initial denaturation step for $5 \mathrm{~min}$ at $95{ }^{\circ} \mathrm{C}$, followed by 32 cycles of $94{ }^{\circ} \mathrm{C}$ for $1 \mathrm{~min}, 57^{\circ} \mathrm{C}$ for $1 \mathrm{~min}$ and $70{ }^{\circ} \mathrm{C}$ for $1 \mathrm{~min}$, with a final extension step at $72{ }^{\circ} \mathrm{C}$ for $10 \mathrm{~min}$. For TEM, the amplification cycle consisted of $5 \mathrm{~min}$ at $95{ }^{\circ} \mathrm{C}$, followed by 30 cycles of $94{ }^{\circ} \mathrm{C}$ for $30 \mathrm{~s}$, $55{ }^{\circ} \mathrm{C}$ for $1 \mathrm{~min}$ and $72{ }^{\circ} \mathrm{C}$ for $1 \mathrm{~min}$, with extension at $72{ }^{\circ} \mathrm{C}$ for $10 \mathrm{~min}$. For CTX-M, the amplification cycle consisted of $5 \mathrm{~min}$ at $94{ }^{\circ} \mathrm{C}$, followed by 30 cycles of $94{ }^{\circ} \mathrm{C}$ for $30 \mathrm{~s}, 55^{\circ} \mathrm{C}$ for $1 \mathrm{~min}$ and $72{ }^{\circ} \mathrm{C}$ for $1 \mathrm{~min}$, with extension at $72{ }^{\circ} \mathrm{C}$ for $10 \mathrm{~min}$. The amplifications were performed in a programmable PCR thermal cycler (Perkin Elmer). E. coli strain ATCC 25922 was used as a negative control in all PCR assays. The positive control for SHV was K. pneumoniae 6064, whilst the positive control for TEM and CTX-M was E. coli 971.

DNA sequencing. Amplified PCR products for each of the bla $a_{\mathrm{TEM}}$, $b l a_{\mathrm{SHV}}$ and $b l a_{\mathrm{CTX}-\mathrm{M}}$ genes were sent for analysis by an automated DNA sequencing system in the Research Core Facility Laboratory, Health Science Center, Kuwait University. PCR products for the three different genes were purified by ethanol precipitation. Twenty-five microlitres of template suppression reagent was added to the pellet, mixed and finally heated for $2 \mathrm{~min}$ at $95{ }^{\circ} \mathrm{C}$. One microlitre of each PCR product from the previous step was mixed with $3.2 \mathrm{pmol}$ of either a forward or a reverse primer for the three pairs of primers used in the study, and for each sample $8 \mu$ of a dye terminator ready sequence reaction mix was added (Prism Ready Reaction Dye-Deoxy 
Terminator Cycle Sequencing kit; Perkin Elmer). The sequencing PCR was then carried out for 30 cycles of $96{ }^{\circ} \mathrm{C}$ for $20 \mathrm{~s}, 50{ }^{\circ} \mathrm{C}$ for $20 \mathrm{~s}$ and $60{ }^{\circ} \mathrm{C}$ for $4 \mathrm{~min}$. The products were cleaned again as described above and kept on ice until the sequencing reaction was run on an automated AB13100 DNA sequencer (Applied Biosystems). The resulting DNA sequences were compared with $K$. pneumoniae genes from GenBank using BLAST (http://www.ncbi.nlm.nih.gov/ blast).

PFGE. All isolates were analysed by PFGE using a standardized PulseNet protocol as described previously (Ribot et al., 2001). Genomic DNA was digested with $40 \mathrm{U} \mathrm{XbaI}$ restriction endonuclease and separated in a CHEF-DR III electrophoresis system (Bio-Rad Laboratories). The running parameters were as follows: initial pulse $5 \mathrm{~s}$ and final pulse $40 \mathrm{~s}$, at $6 \mathrm{~V} \mathrm{~cm}^{-1}$ for $20 \mathrm{~h}$ at $14{ }^{\circ} \mathrm{C}$. The gels were stained with ethidium bromide and photographed under UV transillumination. Banding patterns were compared visually and interpreted based on published criteria (Tenover et al., 1995).

\section{RESULTS}

The sources and characteristics of the K. pneumoniae isolates are presented in Table 1. All 10 isolates were resistant to cefotaxime, ceftazidime, cefepime, gentamicin, tobramycin and ciprofloxacin but susceptible to tetracycline and trimethoprim-sulfamethoxazole. They were confirmed as ESBL producers using a Vitek 2 AST N020 card, a disc-approximation test, double-disc diffusion and Etest ESBL strips. Figs 1 and 2 show the positive ESBL results obtained using the different test methods.

All $10 \mathrm{~K}$. pneumoniae isolates were screened for the presence of the $\beta$-lactamase genes $b l a_{\mathrm{SHV}}, b l a_{\mathrm{TEM}}$ and $b l a_{\text {CTX-M }}$ by PCR. The results showed that all 10 isolates yielded positive results for $b l a_{\mathrm{CTX}-\mathrm{M}}, b l a_{\mathrm{SHV}}$ and $b l a_{\mathrm{TEM}}$. The results of amplification of the products of the $b l a_{\mathrm{TEM}}$ (858 bp), $b l a_{\mathrm{SHV}}\left(308 \mathrm{bp}\right.$ ) and $b l a_{\mathrm{CTX}-\mathrm{M}}(499 \mathrm{bp})$ genes are presented in Fig. $3(\mathrm{a}-\mathrm{c})$, respectively.

Table 1. Characteristics of K. pneumoniae isolates

All 10 isolates were positive for the SHV-112, TEM-1 and CTX-M-15like enzymes, and were PFGE band pattern A.

\begin{tabular}{|lccll|}
\hline Patient & Source & Date & Age/sex & \multicolumn{1}{c|}{ Diagnosis } \\
\hline 1 & Blood & $2 / 2 / 2006$ & 4 days/M & PT (25 weeks) \\
2 & Blood & $6 / 2 / 2006$ & 5 days/M & PT, RDS \\
3 & Blood & $7 / 2 / 2006$ & 5 days/M & PT, RDS \\
4 & Blood & NS & 5 days/M & PT, RDS \\
5 & Blood & $17 / 2 / 2006$ & 17 days/F & PT, RDS \\
6 & Blood & $4 / 3 / 2006$ & 32 days/F & PT, RDS \\
7 & Blood & $18 / 2 / 2006$ & NS/F & RDS \\
8 & Blood & $7 / 8 / 2005$ & 6 days/F & - \\
S27 & Finger & - & Adult/F & IC \\
S30 & Finger & - & Adult/F & IC \\
& & & & \\
\hline
\end{tabular}

NS, Not specified.

${ }^{\star} \mathrm{PT}$, Preterm birth; RDS, respiratory disease syndrome; IC, infection control.

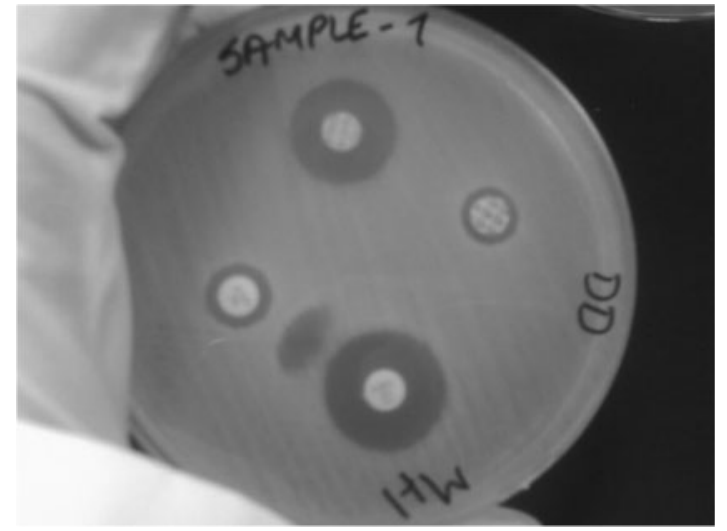

Fig. 1. Results of a disc-approximation test showing a positive ESBL reaction between amoxicillin-clavulanate and ceftazidime discs.

The amplified products of the $b l a_{\mathrm{TEM}}, b l a_{\mathrm{SHV}}$ and $b l a_{\mathrm{CTX}-\mathrm{M}}$ genes were sequenced and their sequences were compared with ESBL sequences in GenBank to determine the ESBL types. The results of BLAST searches revealed that the TEM sequences had $100 \%$ identity to TEM-1 sequences in GenBank. Similarly, the product of $b a_{\text {СтХ-м }}$ had $100 \%$ identity to the CTX-M-15 enzyme. As only 499 bp of the gene was sequenced, we termed it CTX-M-15-like. The bla $a_{\text {SHV }}$ amplification product showed $100 \%$ identity to the SHV-112 enzyme. SHV-112 has an amino acid change at position 253 of the protein product, in which asparagine (AAT) is changed to aspartic acid (GAT).

All $10 \mathrm{~K}$. pneumoniae isolates were characterized further by typing using PFGE to ascertain their genetic relatedness. The results presented in Fig. 4 showed that they all had identical banding patterns, including those from the two healthcare workers and the isolate obtained in 2005 (not shown).



Fig. 2. ESBL detection by a double-disc diffusion test showing clear zones of inhibition for all antibiotics tested. 

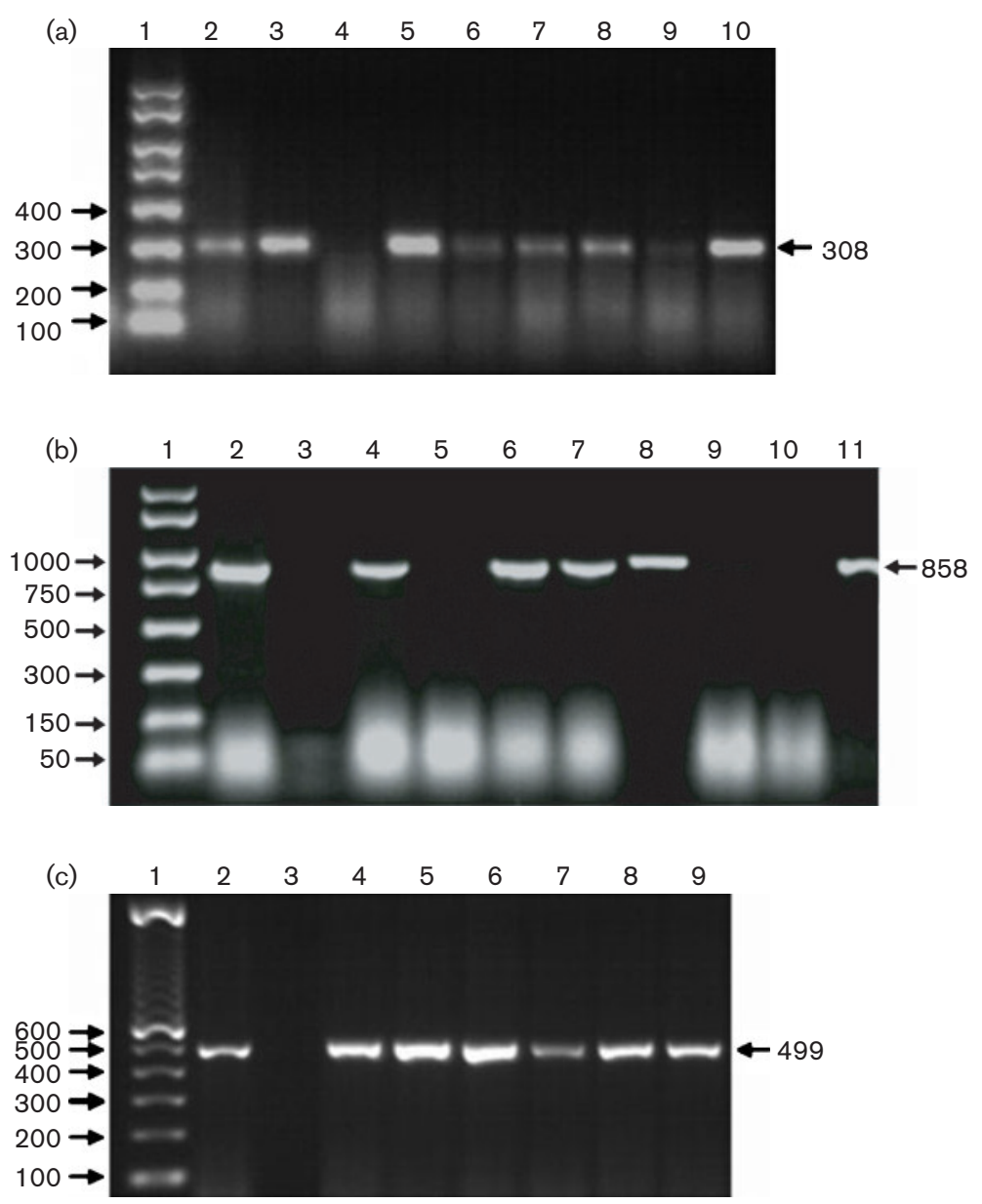

Fig. 3. Gel electrophoresis for PCRs performed in this study. (a) Presence of the bla amplicon with a molecular size of $308 \mathrm{bp}$ (lanes 3 and 5-10; isolates 2-8, respectively; Table 1). Lane 1, 100 bp DNA marker; lanes 2 and 4, positive- and negative-control strains, respectively. (b) Presence of the b/a $a_{\mathrm{TEM}}$ amplicon with a molecular size of $858 \mathrm{bp}$ (lanes 2, 4 and 6-8; isolates 2-6; Table 1). Lane 1, 100 bp DNA marker; lanes 3, 5, 9 and 10 , negative-control strains; lane 11 , positivecontrol strain. (c) Presence of the bla amplicon with a molecular size of $499 \mathrm{bp}$ (lanes 4-9; isolates 1-6; Table 1). Lane 1, 100 bp DNA marker; lane 2, positive-control strain; lane 3 , negative-control strain.

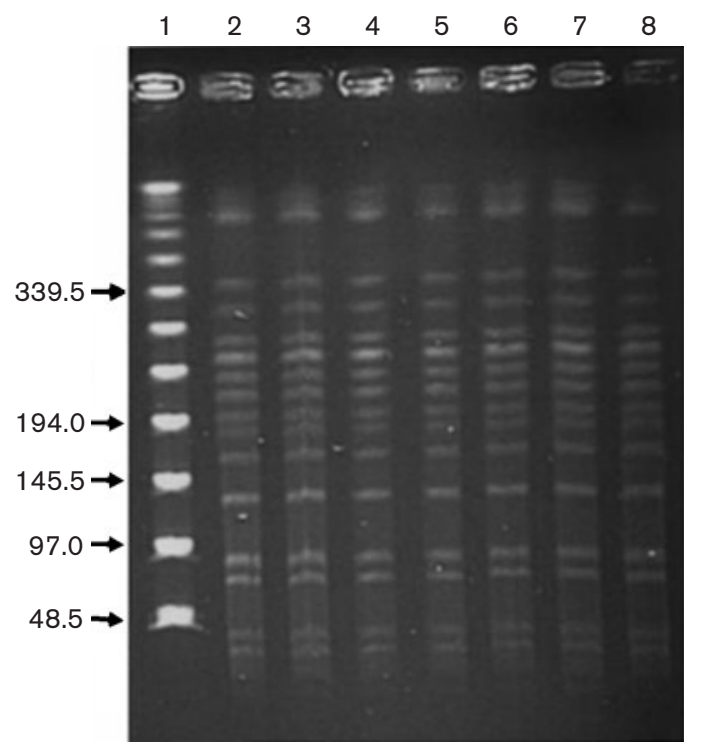

Fig. 4. PFGE results. Lane 1, size markers (bp); lanes 2-8, identical patterns for the isolates studied (isolates 1-7; Table 1).

\section{DISCUSSION}

This study presents evidence that a clone of ESBLproducing K. pneumoniae caused bloodstream infections among pre-term babies in a NICU of a Kuwaiti hospital. ESBL-producing K. pneumoniae has also been reported to cause outbreaks of infections in NICUs in other countries (Mantilla et al., 2006; Shenoy et al., 2007; Kristof et al., 2007). Although susceptible to tetracycline and trimethoprim-sulfamethoxazole, the K. pneumoniae clone presented here was multiresistant, with resistance to cefotaxime, ceftazidime, cefepime, gentamicin, tobramycin and ciprofloxacin, thereby compromising the use of extendedspectrum cephalosporins, quinolones and aminoglycosides as therapeutic options. Similarly, Jain et al. (2003) showed that ESBL-producing organisms were resistant to ampicillin, cotrimoxazole, tetracycline and gentamicin (Jain et al., 2003).

PFGE analysis revealed that all 10 isolates, including those from the neonates and healthcare workers, were identical, indicating that a single clone of $K$. pneumoniae was involved. This suggests that the two healthcare workers either acquired the bacteria from the neonates or may have been involved in its transmission at some point. The role of healthcare workers in the transmission of outbreak strains 
is well documented in the literature (Heritage et al., 1999). Furthermore, the finding that a $K$. pneumoniae strain isolated from a neonate who was admitted to the facility in 2005 was identical to the isolates that were obtained in 2006 implies that the strain had been introduced into the facility prior to 2006 when more cases were found. This suggests that, in addition to the possible contribution of healthcare workers in its transmission, the environment may also have contributed to its maintenance in the NICU. Unfortunately, no isolate from the environment was available for comparison with the current outbreak strain.

DNA amplification and sequencing of the amplified ESBL genes from the 10 isolates revealed that all isolates contained the genes for TEM-1, CTX-M-15 and SHV112. Since the description of ESBL enzymes in the 1980s (Huang et al., 2006), ESBL-producing members of the Enterobacteriaceae, especially E. coli and K. pneumoniae, have been reported to cause serious infections in the community as well as in hospitals in different parts of the world (Pitout et al., 2005; Huang et al., 2006; Lee et al., 2006; Naseer et al., 2007; Mendonça et al., 2007; Rodríguez-Baño et al., 2006), with significant economic costs (Lee et al., 2006; Schwaber et al., 2006). However, in recent years, organisms producing the CTX-M-15 enzyme have become more widespread in several countries (Livermore \& Hawkey, 2005; Lavollay et al., 2006; Naseer et al., 2007; Valenzuela de Silva et al., 2006; Mendonça et al., 2007) and have also been reported in isolates obtained in Kuwait (Sonnevend et al., 2006). It is remarkable that all 10 isolates contained genes for three ESBLs, highlighting the growing complexity of antibacterial resistance problems. It is interesting that these isolates were positive for a novel SHV enzyme (SHV-112) that was recently detected in $K$. pneumoniae isolates from another hospital in Kuwait (A. A. Dashti and M. M. Jadaon, unpublished results; GenBank accession no. EU477409). SHV-112 has an $A \rightarrow G$ change at position 253 of the protein product, in which asparagine (AAT) is changed to aspartic acid (GAT). The detection of SHV-112 in these isolates suggests that SHV-112 had been present in $K$. pneumoniae in Kuwait at least since 2005, long before it was detected in 2008, and that it may be widespread in Kuwaiti hospitals. An extensive screening of K. pneumoniae and other ESBL-producing members of the Enterobacteriaceae is necessary to establish the prevalence of this novel enzyme in bacterial isolates from different Kuwaiti hospitals.

In conclusion, the results of this study have demonstrated the transmission of a clone of ESBL-producing $K$. pneumoniae among neonates and healthcare workers in a NICU in Kuwait that may have emerged 5 years previously. Further studies are needed to determine whether this clone is also spreading in other Kuwaiti hospitals.

\section{ACKNOWLEDGEMENTS}

The authors wish to thank Mr Berneesh T. Jose and Ms Ainne Sahni for the technical work, and the Research Core Laboratory of the
Health Sciences Centre, Kuwait University, for their help in performing DNA sequencing for this project (project number GM01/01).

\section{REFERENCES}

Al-Zarouni, M., Senok, A., Rashid, F., Al-Jesmi, S. M. \& Panigrahi, D. (2008). Prevalence and antimicrobial susceptibility pattern of extended-spectrum $\beta$-lactamase-producing Enterobacteriaceae in the United Arab Emirates. Med Princ Pract 17, 32-36.

Ben-Ami, R., Schwaber, M. J., Navon-Venezia, S., Schwartz, D., Giladi, M., Chmelnitsky, I., Leavitt, A. \& Carmel, Y. (2006). Influx of extended-spectrum $\beta$-lactamase-producing Enterobacteriaceae into the hospital. Clin Infect Dis 42, 925-934.

Bonnet, R. (2004). Growing group of extended-spectrum $\beta$ lactamases: the CTX-M enzymes. Antimicrob Agents Chemother 48, $1-14$.

Bradford, P. A. (2001). Extended-spectrum $\beta$-lactamases in the 21 st century: characterization, epidemiology, and detection of this important resistance threat. Clin Microbiol Rev 14, 933-951.

Canton, R. \& Coque, T. M. (2006). The CTX-M $\beta$-lactamase pandemic. Curr Opin Microbiol 9, 466-475.

Cormican, M. G., Marshall, S. A. \& Jones, R. N. (1996). Detection of extended spectrum $\beta$-lactamase (ESBL)-producing strains by the Etest ESBL screen. J Clin Microbiol 34, 1880-1884.

Dashti, A. A. \& West, P. W. (2007). Extended-spectrum $\beta$-lactamaseproducing Escherichia coli isolated in the Al-Amiri hospital in 2003 and compared with isolates from the Farwania hospital outbreak in 1994-96 in Kuwait. J Chemother 19, 271-276.

Dashti, A. A., West, P., Paton, R. \& Amyes, S. G. (2006). Characterization of extended-spectrum $\beta$-lactamase (ESBL)-producing Kuwait and UK strains identified by the VITEK system, and subsequent comparison of the VITEK system with other commercial ESBL-testing systems using these strains. J Med Microbiol 55, 417-421.

Dimitrov, T. S., Udo, E. E., Emara, M., Awni, F. \& Passadilla, R. (2004). Etiology and antibiotic susceptibility patterns of community-acquired urinary tract infection in a Kuwait hospital. Med Princ Pract 13, 334339.

Du Bois, S. K., Marriott, M. S. \& Amyes, S. G. B. (1995). TEM- and SHV-derived extended-spectrum $\beta$-lactamases: relationship between selection, structure and function. J Antimicrob Chemother 35, 7-22.

El-Khizzi, N. A. \& Bakheshwain, S. M. (2006). Prevalence of extended-spectrum $\beta$-lactamases among Enterobacteriaceae isolated from blood culture in a tertiary care hospital. Saudi Med J 27, 37-40.

Hanson, N. D., Thomson, K. S., Moland, E. S., Sanders, C. C., Berthold, G. \& Penn, R. G. (1999). Molecular characterization of a multiply resistant Klebsiella pneumoniae encoding ESBLs and a plasmid-mediated AmpC. J Antimicrob Chemother 44, 377-380.

Heritage, J., M'Zali, F. H., Gascoyne-Binzi, D. \& Hawkey, P. M. (1999). Evolution and spread of SHV extended-spectrum $\beta$ lactamases in Gram-negative bacteria. J Antimicrob Chemother 44, 309-318.

Huang, S.-S., Lee, M.-H. \& Leu, H.-S. (2006). Bacteremia due to extended-spectrum $\beta$-lactamase-producing Enterobacteriaceae other than Escherichia coli and Klebsiella. J Microbiol Immunol Infect 39, 496-502.

Jacoby, G. A. (2006). $\beta$-Lactamase nomenclature. Antimicrob Agents Chemother 50, 1123-1129.

Jain, A., Roy, I., Gupta, M. K., Kumar, M. \& Agarwal, S. K. (2003). Prevalence of extended-spectrum $\beta$-lactamase-producing Gram- 
negative bacteria in septicaemic neonates in a tertiary care hospital. J Med Microbiol 52, 421-425.

Jamal, W., Rotimi, V. O., Khodakhast, F., Saleem, R., Pazhoor, A. \& Al Hashim, G. (2005). Prevalence of extended-spectrum $\beta$-lactamase in Enterobacteriaceae, Pseudomonas and Stenotrophomonas as determined by the VITEK 2 and Etest systems in a Kuwait teaching hospital. Med Princ Pract 14, 325-331.

Jonathan, N. (2005). Screening for extended-spectrum $\beta$-lactamaseproducing pathogenic enterobacteria in district general hospitals. J Clin Microbiol 43, 1488-1490.

Kader, A. A. \& Angamuthu, K. (2005). Extended-spectrum $\beta$ lactamases in urinary isolates of Escherichia coli, Klebsiella pneumoniae and other Gram-negative bacteria in a hospital in Eastern Province, Saudi Arabia. Saudi Med J 26, 956-959.

Kader, A. A., Kumar, A. \& Kamath, K. A. (2007). Faecal carriage of extended-spectrum $\beta$-lactamase-producing Escherichia coli and Klebsiella pneumoniae in patients and asymptomatic healthy individuals. Infect Control Hosp Epidemiol 28, 1114-1116.

Kristof, K., Szabo, D., Marsh, J. W., Cser, V., Janik, L., Rozgonyi, F., Nobilis, A., Nagy, K. \& Paterson, D. L. (2007). Extended-spectrum $\beta$ lactamase-producing Klebsiella spp. in a neonatal intensive care unit: risk factors for the infection and the dynamics of molecular epidemiology. Eur J Clin Microbiol Infect Dis 26, 563-570.

Lavollay, M., Mamlouk, K., Frank, T., Akpabie, A., Burghoffer, B., Ben Redjeb, S., Bercion, R., Gautier, V. \& Arlet, G. (2006). Clonal dissemination of a CTX-M-15 $\beta$-lactamase-producing Escherichia coli strain in the Paris area, Tunis and Bangui. Antimicrob Agents Chemother 50, 2433-2438.

Lee, S. Y., Kotapati, S., Kuti, J. L., Nightingale, C. H. \& Nicolau, D. P. (2006). Impact of extended-spectrum $\beta$-lactamase-producing Escherichia coli and Klebsiella species on clinical outcomes and hospital costs: a matched cohort study. Infect Control Hosp Epidemiol 27, 1226-1232.

Livermore, D. M. \& Hawkey, P. M. (2005). CTX-M: changing the face of ESBLs in the UK. J Antimicrob Chemother 56, 451-454.

Livermore, D. M. \& Yuan, M. (1996). Antibiotic resistance and production of extended-spectrum $\beta$-lactamases amongst Klebsiella spp. from intensive care units in Europe. J Antimicrob Chemother 38, 409-424.

Mantilla, J. R., Reguero, M. T., González, E. B., García, I. A., Leal, A. L., Espinal, P. A., Alpuche, C., Valderrama, I. A., Garzón, M. I. \& Olarte, N. M. (2006). Molecular characterization of an outbreak caused by CTX-M-12 producing Klebsiella pneumoniae in a Colombian hospital's neonatal intensive care unit. Biomedica 26, 408-414 (in Spanish).

Mendonça, N., Leitão, J., Manageiro, V. \& Ferreira, E. (2007). Spread of extended-spectrum $\beta$-lactamase CTX-M-producing Escherichia coli clinical isolates in community and nosocomial environments in Portugal. Antimicrob Agents Chemother 51, 1946-1955.

Naseer, U., Natås, O. B., Haldorsen, B. C., Bue, B., Grundt, H., Walsh, T. R. \& Sundsfjord, A. (2007). Nosocomial outbreak of CTX-M-15producing E. coli in Norway. APMIS 115, 120-126.

Panhotra, B. R., Saxena, A. K. \& AI-Ghamdi, A. M. (2004). Extendedspectrum $\beta$-lactamase-producing Klebsiella pneumoniae acquired bacteremia. Risk factors and clinical outcome. Saudi Med J 25, 1871-1876.
Paterson, D. L. \& Bonomo, R. A. (2005). Extended-spectrum $\beta$ lactamases: a clinical update. Clin Microbiol Rev 18, 657-686.

Paterson, D. L., Hujer, K. M., Hujer, A. M., Yeiser, B., Bonomo, M. D., Rice, L. B., Bonomo, R. A. \& the International Klebsiella Study Group (2003). Extended-spectrum $\beta$-lactamases in Klebsiella pneumoniae bloodstream isolates from seven countries: dominance and widespread prevalence of SHV- and CTX-M-type $\beta$-lactamases. Antimicrob Agents Chemother 47, 3554-3560.

Pitout, J. D., Nordman, P., Laupland, K. B. \& Poirel, L. (2005). Emergence of Enterobacteriaceae producing extended-spectrum $\beta$ lactamases (ESBLs) in the community. J Antimicrob Chemother 56, 52-59.

Rafay, A. M., Al-Muharrmi, Z. \& Toki, R. (2007). Prevalence of extended-spectrum $\beta$-lactamases producing isolates over a 1-year period at a university hospital in Oman. Saudi Med J 28, 22-27.

Ribot, E. M., Fitzgerald, C., Kubota, K., Swaminathan, B. \& Barrett, T. J. (2001). Rapid pulsed-field gel electrophoresis protocol for subtyping of Campylobacter jejuni. J Clin Microbiol 39, 1889-1894.

Rodríguez-Baño, J., Navarro, M. D., Romero, L., Muniain, M. A., de Cueto, M., Ríos, M. J., Hernández, J. R. \& Pascual, A. (2006). Bacteremia due to extended-spectrum $\beta$-lactamase-producing Escherichia coli in the CTX-M era: a new clinical challenge. Clin Infect Dis 43, 1407-1414.

Sanders, C. C., Barry, A. L., Washington, J. A., Moland, E. S., Traczewski, M. M., Knapp, C. \& Mulder, R. (1996). Detection of extended-spectrum $\beta$-lactamase-producing members of the family Enterobacteriaceae with Vitek ESBL test. J Clin Microbiol 34, 29973001.

Schwaber, M. J., Navon-Venezia, S., Kaye, K. S., Ben-Ami, R., Schwartz, D. \& Carmeli, Y. (2006). Clinical and economic impact of bacteremia with extended-spectrum- $\beta$-lactamase-producing Enterobacteriaceae. Antimicrob Agents Chemother 50, 1257-1262.

Shenoy, S., Hegde, A., Dominic, S. R., Kamath, S. \& Arvind, N. (2007). An outbreak of extended spectrum $\beta$-lactamase producing Klebsiella pneumoniae in a neonatal intensive care unit. Indian $J$ Pathol Microbiol 50, 669-670.

Sonnevend, A., AI Dhaheri, K., Mag, T., Herpay, M., Kolodziejek, J., Nowotny, N., Usmani, A., Sheikh, F. A. \& Pal, T. (2006). CTX-M-15producing multidrug-resistant enteroaggregative Escherichia coli in the United Arab Emirates. Clin Microbiol Infect 12, 582-585.

Tenover, F. C., Arbeit, R. D., Goering, R. V., Mickelsen, P. A., Murray, B. E., Persing, D. H. \& Swaminathan, B. (1995). Interpreting chromosomal DNA restriction patterns produced by pulsed-field gel electrophoresis. J Clin Microbiol 33, 2233-2239.

Valenzuela de Silva, E. M., Mantilla Anaya, J. R., Reguero Reza, M. T., González Mejía, E. B., Pulido Manrique, I. Y., Dario Llerena, I. \& Velandia, D. (2006). Detection of CTX-M-1, CTX-M-15 and CTX-M2 in clinical isolates of Enterobacteriaceae in Bogota, Colombia. J Clin Microbiol 44, 1919-1920.

Valverde, A., Coque, T. M., Sánchez-Moreno, M. P., Rollan, A., Baquero, F. \& Cantón, R. (2004). Dramatic increase in prevalence of fecal carriage of extended-spectrum $\beta$-lactamase-producing Enterobacteriacecae during nonoutbreak situations in Spain. J Clin Microbiol 42, 4769-4775.

Wallace, M. R., Johnson, A. P., Daniel, M., Malde, M. \& Yousif, A. A. (1995). Sequential emergence of multi-resistant Klebsiella pneumoniae in Bahrain. J Hosp Infect 31, 247-252. 